\title{
Studies on the Mercuric Oxide Electrode. II. The Effect of Various Additives on the Discharge Reaction of the Mercuric Oxide Electrode*
}

\author{
Shiro Yosizawa, Zenichiro Takehara, and Yasumichi Namba
}

Department of Industrial Chemistry, Faculty of Engineering, Kyoto University, Yoshida, Kyoto

\begin{abstract}
The effects of various additives which were introduced into the mercuric oxide electrode were studied by the same methods reported in the previous paper $^{1}$. The electrode which consisted of the thin film of mercuric oxide formed by anodic oxidation in potassium hydroxide solution was adopted. Additives were introduced in the following two methods; (1) additives were introduced into mercury used as the starting electrode by amalgamation, and in this method, $\mathrm{Ag}, \mathrm{Au}, \mathrm{Cu}, \mathrm{Zn}, \mathrm{Cd}, \mathrm{In}, \mathrm{Tl}, \mathrm{Sn}$ and $\mathrm{Pb}$ were selected as the additives, (2) additives were introduced into electrolyte, and in this method, $\operatorname{Ag}_{2} \mathrm{O}$, $\mathrm{ZnO}, \mathrm{CdO}, \mathrm{In}(\mathrm{OH})_{3}, \mathrm{SnO}, \mathrm{Fe}(\mathrm{OH})_{3}, \mathrm{NiO}, \mathrm{La}_{2} \mathrm{O}_{3}$ and $\mathrm{Ce}(\mathrm{OH})_{4}$ were selected as the additives. By these additives, disproportionate reaction of an intermediate product $\left(\mathrm{Hg}_{2} \mathrm{O}\right.$ or $\left.\mathrm{HgOH}\right)$ formed by the discharge was affected exceedingly, and therefore, the overpotential of the discharge reaction was changed. By addition of metallic $\mathrm{Cu}, \mathrm{Zn}, \mathrm{Cd}, \mathrm{In}, \mathrm{Tl}, \mathrm{Sn}$ or $\mathrm{Pb}$, the overpotential of the discharge reaction was decreased exceedingly, but the selfdischarge reaction of the mercuric oxide electrode was accelerated, so the utilization rate of the mercuric oxide became much smaller. By addition of $\mathrm{ZnO}$, $\mathrm{CdO}, \mathrm{Fe}(\mathrm{OH})_{3}, \mathrm{NiO}$ or $\mathrm{La}_{2} \mathrm{O}_{3}$, the overpotential of the discharge reaction was decreased, and moreover, the self-discharge reaction of the mercuric oxide electrode was retarded, i.e., $\mathrm{ZnO}, \mathrm{CdO}, \mathrm{Fe}(\mathrm{OH})_{3}, \mathrm{NiO}$ or $\mathrm{La}_{2} \mathrm{O}_{3}$ were the most excellent additives for improvement of the discharge characteristics of the mercuric oxide electrode.
\end{abstract}

\section{Introduction}

It was reported in the previous paper ${ }^{1)}$ that the discharge reaction of the mercuric oxide electrode proceeded through an intermediate product which accumulated on the electrode surface and decomposed into $\mathrm{HgO}$ and $\mathrm{Hg}$ by the disproportionate reaction. As this disproportionate reaction in a rate determining step for the discharge reaction, decreasing of the discharge overpotential, which means improvement of the discharge performance should be possible by adding a trace of substances promoting the disproportionate reaction into the mercuric oxide electrode. With a view to confirming these phenomena, the discharge performance was studied in the case of adding a trace of various additives in the $\mathrm{HgO}$ active mass.

\section{Experimental}

Experiments were carried out by the same method as described in the previous paper ${ }^{1}$, and as the mercuric oxide electrode, the thin film prepared by anodic oxidation of $\mathrm{Hg}$ surface in $1 \mathrm{~N} \mathrm{KOH}$ was adopted. The apparent surface area of the electrode was $3 \mathrm{~cm}^{2}$, and $\mathrm{Hg}$ used for our experiments was a pure one in which no trace of impurities could be observed by spectroscopic analysis. $1 \mathrm{~N} \mathrm{KOH}$ electrolyte, saturated with nitrogen gas, was used after eliminating $\mathrm{CO}_{3}{ }^{2-}$ ion by $\mathrm{Ba}(\mathrm{OH})_{2}$ solution.

Various kinds of additives were put into the $\mathrm{HgO}$ active mass by the following two methods.

(1) A trace of additive metals was added to $\mathrm{Hg}$ of the starting electrode as mercury amalgam, whose surface was anodically oxidized and was pregnant with these additives.

(2) $\mathrm{KOH}$ electrolyte was saturated with those additives of metal hydroxides or oxides which might

* This paper was reported at the 29th meeting of the Electrochemical Society of Japan, April 30, 1962. The original written in Japanese can be seen in Denki Kagaku, 30, 741 (1962). 
be soluble in the state of metal complex ions.

In this solution the surface of pure $\mathrm{Hg}$ was anodically oxidized and the thin film of $\mathrm{HgO}$ formed was discharged in the same solution*.

In the study on the effects of the additives by the amalgamation method, easily amalgamating metals, such as $\mathrm{Cu}, \mathrm{Ag}, \mathrm{Au}, \mathrm{Zn}, \mathrm{Cd}, \mathrm{In}, \mathrm{Tl}, \mathrm{Sn}, \mathrm{Pb}$ and $\mathrm{Bi}$ were adopted as the additives. And the amalgam concentration was varied from 1 to $0.005 \mathrm{~mol} \%$ in our study. When the surface of the amalgam of $\mathrm{Ag}$ or $\mathrm{Au}$ was oxidized anodically at constant current in $\mathrm{KOH}$ electrolyte, yellow $\mathrm{HgO}$ was produced on the electrode surface immediately after passing the current, like that of pure Hg. But in the case of anodic oxidation of amalgams of the others at constant current, the additive metals were dissolved into the electrolyte by the ionization reaction before producing $\mathrm{HgO}$, or the electrode surface was covered with their oxides or hydroxides. When the concentration of the additives was $0.1 \mathrm{~mol} \%$ or more, $\mathrm{HgO}$ could not be prepared at all on the electrode surface by anodic oxidation, because the ionization potential of these additives was so negative that the whole electrode surface was covered with their oxide or hydroxide films. Therefore, the amalgam concentration was diluted to exceedingly small amount i.e., 0.01 to $0.005 \mathrm{~mol} \%$, except the amalgam of $\mathrm{Ag}$ or $\mathrm{Au}$.

In the study on the effects of the additives by the saturation method the substances such as $\mathrm{Ag}_{2} \mathrm{O}$, $\mathrm{ZnO}, \mathrm{CdO}, \mathrm{In}(\mathrm{OH})_{3}, \mathrm{SnO}, \mathrm{Fe}(\mathrm{OH})_{3}, \mathrm{NiO}$, $\mathrm{La}_{2} \mathrm{O}_{3}$ and $\mathrm{Ce}(\mathrm{OH})_{4}$ were chosen as the additives.

Fig. 1 shows the representative potentialtime curves for anodic oxidation of the electrode containing various additives at constant current of $6 \mathrm{~mA}$ (current density $2 \mathrm{~mA} / \mathrm{cm}^{2}$ ) in $30^{\circ} \mathrm{C}, 1 \mathrm{~N} \mathrm{KOH}$ electrolyte. When the electrode containing $\mathrm{Ag}$ or $\mathrm{Au}$ was anodically oxidized in $\mathrm{KOH}$ electrolyte, $\mathrm{HgO}$ was produced immediately after passing the current. When the electrode containing In was anodically oxidized, however, it was found that the charging potential stayed much longer at the potential producing $\mathrm{HgO}$ and also the quantity of electricity for producing $\mathrm{HgO}$ was much larger. It is necessary for raising the potential rapidly from this potential range that the whole electrode surface should be covered with the oxide film. When the electrode containing In was anodically oxidized in $\mathrm{KOH}$ electrolyte, the dissolution reaction by ionization of In occurred at first and then the polarization resistance increased, until

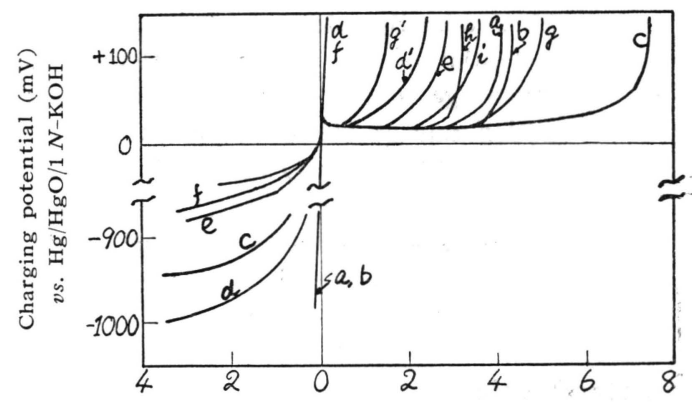

Before production of $\mathrm{HgO} \leftarrow \mid \rightarrow$ After production of $\mathrm{HgO}$ Time $(\mathrm{min})$

a : for no additive

$\mathrm{b}$ : for $\mathrm{Ag} 1 \mathrm{~mol} \%$ by the amalgamation method

c : for In $0.005 \mathrm{~mol} \%$ by the amalgamation method

$\mathrm{d}$ : for $\mathrm{Cd} 0.005 \mathrm{~mol} \%$ by the amalgamation method

$d^{\prime}$ : for the sample of (d) after three cycles of discharge and charge.

e : for $\mathrm{Pb} 0.01 \mathrm{~mol} \%$ by the amalgamation method

$f$ : for $\mathrm{Bi} 0.005 \mathrm{~mol} \%$ by the amalgamation method

$\mathrm{g}$ : for CdO by the saturation method

$\mathrm{g}^{\prime}$ : for the sample of ( $\mathrm{g}$ ) after three cycles of discharge and charge

h : for $\mathrm{NiO}$ by the saturation method

$\mathrm{i}$ : for $\mathrm{La}_{2} \mathrm{O}_{3}$ by the saturation method

Fig. 1 Potential-time curves for anodic oxidation of the $\mathrm{Hg}$ surface added the various additives at $6 \mathrm{~mA}$ (c.d. $2 \mathrm{~mA} / \mathrm{cm}^{2}$ ) $\mathrm{HgO}$ began to produce on the electrode surface with rapid rising of the potential, which followed to the constant voltage, forming $\mathrm{HgO}$ on the whole surface. For the additive of In, the self-discharge was exceedingly large, as will be discussed later in detail. A part of $\mathrm{HgO}$ formed in this potential range decomposed due to the self-discharge, so that much quantity of electricity was necessary for covering the whole surface with $\mathrm{HgO}$. So, $\mathrm{HgO}$ could not be formed on the electrode surface by anodic oxi-

* For simplicity, the former (1) is called the amalgamation method and the latter (2) the saturation method. 
dation at a current lower than the self-discharge current*. This indicates that HgO formed by anodic oxidation at a lower current, i.e. $1 \mathrm{~mA}$, decomposed without delay. All the additives except $\mathrm{Ag}$ and $\mathrm{Au}$ showed this phenomenon. The electrode surface containing $\mathrm{Bi}$ was covered with the violet film due to the bismuth oxide immediately after slight charging, so $\mathrm{HgO}$ could not be formed on the electrode surface by anodic oxidation. $\mathrm{Cd}$ or $\mathrm{Sn}$ showed the same result as that of $\mathrm{Bi}$ except that the oxide or the hydroxide formed during charge was granular, not filmy. A part of these additives could be removed to different phase from $\mathrm{HgO}$ after several cycles of charge and discharge, therefore $\mathrm{HgO}$ could be formed on the electrode surface by anodic oxidation after several cycles.

When $\mathrm{Hg}$ surface was anodically oxidized in $1 \mathrm{~N} \mathrm{KOH}$ electrolyte saturated with additive substances, potential-time curves similar to that for no additive could be obtained.

When the overpotential became $50 \mathrm{mV}$, anodic oxidation was stopped, and then discharge tests were started at once. The quantity of electricity consumed by anodic oxidation at the potential range producing $\mathrm{HgO}$ was calculated as the quantity of charging electricity.

\section{Results and Discussion}

The thin film of $\mathrm{HgO}$ formed by anodic oxidation was discharged at constant, i.e. $1 \mathrm{ma}$, in $30^{\circ} \mathrm{C}, 1 \mathrm{~N} \mathrm{KOH}$ elctrolyte. Figs. 2 and 3 show the discharge potential-time curves for constant current discharge of the mercuric oxide electrode containing the additives by the amalgamation method and by the saturation method, respectively. Fig. 3 (a) and Fig. 3 (b) show the discharge curves for the oxides or the hydroxides of easily amalgamating metals and for those of not easily amalgamating metals generally named transition metals, respectively. In Fig. 2 and Fig. 3 yellow $\mathrm{HgO}$ could not be observed on the electrode surface after rapid increase of the discharge overpotential. Accordingly it is considered that $\mathrm{HgO}$ is decomposed completely in this state. However, the discharge capacity could not be recovered $100 \%$ due to the decomposition of $\mathrm{HgO}$ by the self-discharge during charge and

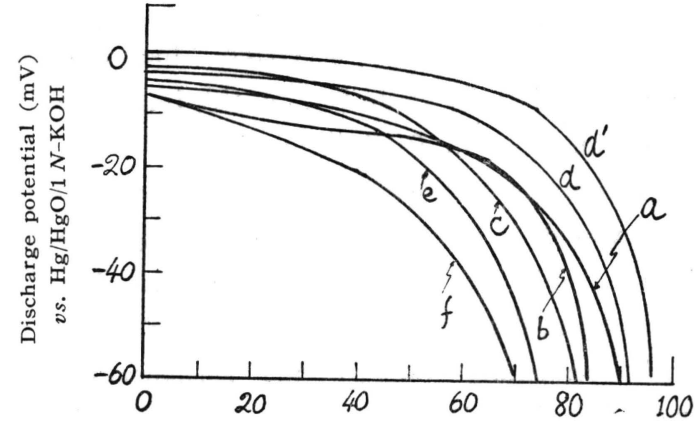

Ratio of the discharge capacity to the charge capacity $(\%)$

a : for no additive

$\mathrm{b}$ : for $\mathrm{Cu} 0.01 \mathrm{~mol} \%$ by the amalgamation method

c : for $\mathrm{Ag} 1 \mathrm{~mol} \%$ by the amalgamation method

d : for Au $0.5 \mathrm{~mol} \%$ by the amalgamation method

e : for $\mathrm{Zn} 0.01 \mathrm{~mol} \%$ by the amalgamation method

$f$ : for In $0.005 \mathrm{~mol} \%$ by the amalgamation method

$\mathrm{g}$ : for $\mathrm{Sn} 0.005 \mathrm{~mol} \%$ by the amalgamation method

h : for $\mathrm{Pb} 0.01 \mathrm{~mol} \%$ by the amalgamation method

$\mathrm{i}$ : for $\mathrm{Tl} 0.01 \mathrm{~mol} \%$ by the amalgamation method

$\mathrm{j}$ : for Cd $0.005 \mathrm{~mol} \%$ by the amalgamation method (Experiments in $30^{\circ} \mathrm{C} 1 \mathrm{~N}$-KOH electrolyte)

Fig. 2 Potential-time curves for the constant current discharge $(1 \mathrm{~mA})$ of the mercuric oxide electrode by the amalgamation method

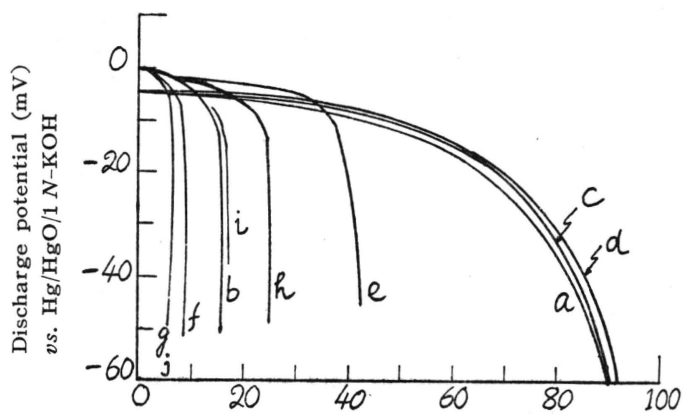

Ratio of the discharge capacity to the charge capacity $(\%)$

a : for no additive

b : for $\mathrm{Ag}_{2} \mathrm{O}$ by the saturation method

c : for $\mathrm{ZnO}$ by the saturation method

d : for $\mathrm{CdO}$ by the saturation method

$d^{\prime}$ : for the sample of (d) after three cycles of charge and discharge

e : for $\operatorname{In}(\mathrm{OH})_{3}$ by the saturation method

$f$ : for $\mathrm{SnO}$ by the saturation method (Experiments in $30^{\circ} \mathrm{C} 1 \mathrm{~N}-\mathrm{KOH}$ electrolyte)

Fig. 3 (a) Potential-time curves for the constant current discharge $(1 \mathrm{~mA})$ of the mercuric oxide electrode by the saturation method

* For example, by anodic oxidation at $1 \mathrm{ma}$ the potential did not rise even after a few hours from constant value at which $\mathrm{HgO}$ should be formed and yellow $\mathrm{HgO}$ could not be observed on the electrode surface. 
discharge. So, Fig. 2 and Fig. 3 will be discussed from the standpoint of both the discharge overpotential and the self-discharge.

It was found that $\mathrm{Ag}$ or $\mathrm{Au}$ added by the amalgamation method decreased the selfdischarge of $\mathrm{HgO}$, while $\mathrm{Cu}, \mathrm{Zn}, \mathrm{Cd}, \mathrm{In}, \mathrm{Tl}, \mathrm{Sn}$ or $\mathrm{Pb}$ increased it. Particularly, for, $\mathrm{Cd}, \mathrm{Sn}$ or In, this action was exceedingly large, so $\mathrm{HgO}$ decomposed of itself even at the standing state in the $\mathrm{KOH}$ electrolyte after charging. For example, at the use of the mercuric oxide electrode containing $\mathrm{Cd}$ by the amalgamation method, yellow $\mathrm{HgO}$ formed on the electrode surface by anodic oxidation at $6 \mathrm{ma}$, decomposed completely within six minutes.

With a view to confirming these phenomena, the potential decay and growth after closing and opening of the circuit during discharge were studied for the various additives in the $\mathrm{HgO}$ active mass. Fig. 4 shows the representative examples of those potential changes. Fig. 4 (1) is for no additive and shows rather slow potential changes after closing and opening of the circuit during discharge, and yet the overpotential is larger than the others. The electrode containing $\mathrm{Au}$ added by the amalagamation method showed almost the same result as that for no additive. On the other hand, Fig. 4 (2) is for the use of the electrode containing $\mathrm{Cd}$ added by the amalgamation method and shows the potential decay and growth after closing and opening of the circuit during discharge, which is faster than that of Fig. 4 (1), and the discharge overpotential became exceedingly small. In this case the potential after the fast recovery on the open circuit gradually fell down to negative.

This phenomenon indicates that the discharge reaction is progressing even at the equilibrium state after opening of the circuit. These facts show that $\mathrm{Cd}$ promotes the rate of decomposition of the intermediate product formed during discharge, and so promotes the selfdischarge. The discharge reaction of $\mathrm{HgO}$, as described in the previous paper ${ }^{1)}$, proceeds through two-step reactions of Eq. (1) and Eq. (2).

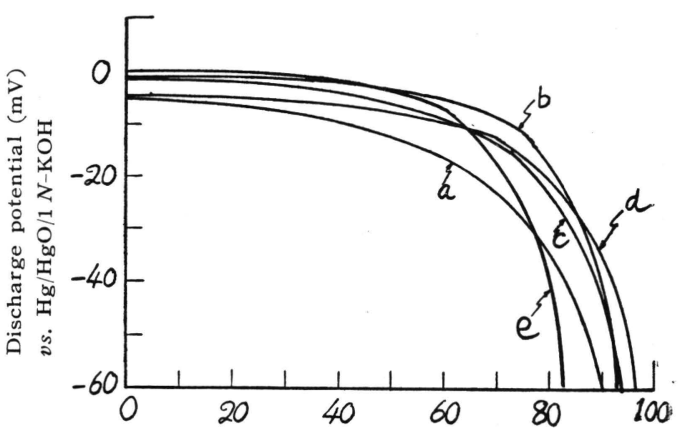

Ratio of the discharge capacity to the charge capacity $(\%)$

a : for no additive

b : for $\mathrm{Fe}(\mathrm{OH})_{3}$ by the saturation method

c : for $\mathrm{NiO}$ by the saturation method

d : for $\mathrm{La}_{2} \mathrm{O}_{3}$ by the saturation method

e : for $\mathrm{Ce}(\mathrm{OH})_{4}$ by the saturation method

(Experiments in $30^{\circ} \mathrm{C}, 1 \mathrm{~N}-\mathrm{KOH}$ electrolyte)

Note : Equilibrium potential after opening of the circuit in Fig. 2 and Fig. 3 are not constant but change within the range of a few milivolts. Accordingly, the overpotential is not always in accord with negativity or positivity of the discharge potential.

Fig. 3 (b) Potential-time curves for the constant discharge current $(1 \mathrm{~mA})$ of the mercuric oxide electrode by the saturation method
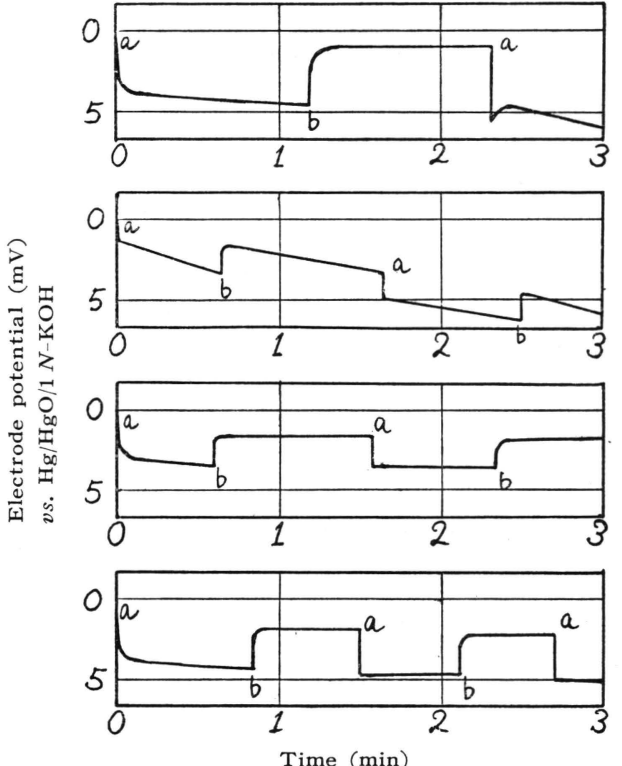

a : discharge at $1 \mathrm{ma}$

b : open circuit

(1) : for no additive

(2) : for Cd $0.005 \mathrm{~mol} \%$ by the amalgamation method

(3) : for $\mathrm{CdO}$ by the saturation method (three cycles of charge and discharge)

(4) : for $\mathrm{La}_{2} \mathrm{O}_{3}$ by the saturation method (Experiments in $30^{\circ} \mathrm{C} 1 \mathrm{~N}$ - $\mathrm{KOH}$ electrolyte)

Fig. 4 Potential growth and decay during discharge for the various additives 


$$
\begin{aligned}
& \mathrm{HgO}+1 / 2 \mathrm{H}_{2} \mathrm{O}+e=\left(\mathrm{Hg}_{2} \mathrm{O}\right)_{1 / 2}+\mathrm{OH}^{-} \\
& 2\left(\mathrm{Hg}_{2} \mathrm{O}\right)_{1 / 2}=\mathrm{HgO}+\mathrm{Hg}
\end{aligned}
$$

So, the self-discharge reaction occurs through the reactions of Eq. (1) and Eq. (2). By adding Cd, the reaction of Eq. (2) was accelerated. For $\mathrm{Cd}$, the following reaction occurs easily

$$
\mathrm{Cd}=\mathrm{Cd}^{2+}+2 \mathrm{e}
$$

Consequently the reaction of Eq. (1), associated with the reaction of Eq. (3) occurred easily due to the existence of $\mathrm{Cd}$, so that the self-discharge of $\mathrm{HgO}$ was promoted. The metals except $\mathrm{Ag}$ or $\mathrm{Au}$ added by the amalgamation method, more or less, decreased the discharge overpotential of $\mathrm{HgO}$ and accelerated the self-discharge like that of $\mathrm{Cd}$.

The mercuric oxide electrode containing $\mathrm{Ag}$ or $\mathrm{Au}$ added by the amalgamation method showed the same discharge overpotential as that for no additive, i.e., Ag or Au scarcely indicated the accelerating action of the reaction of Eq. (2). The potential producing the oxide of $\mathrm{Ag}$ or $\mathrm{Au}$ is more positive than that of $\mathrm{Hg}$, so that the reaction Eq. (1) will not occur spontaneously in the existence of $\mathrm{Ag}$ or $\mathrm{Au}$. Therefore, $\mathrm{Ag}$ or $\mathrm{Au}$ is an affective additive for improving the discharge performance of the mercuric oxide electrode from the standpoint or retarding the self-discharge.

The additives by the saturation method have the action as complex ions and generally should not have the reaction correspond to Eq. (3), so the self-discharge is difficult to occur. For this reason, the additives which have strong catalytic action of the reaction of Eq. (2) must be considered to improve the discharge performance. By adding $\mathrm{Ag}_{2} \mathrm{O}$, the discharge overpotential was as large as that for no additive, but by adding $\mathrm{CdO}$ or $\mathrm{ZnO}$, the discharge overpotential became much smaller and the selfdischarge reaction was not accelerated, as shown in Fig. 3(a). By adding $\mathrm{CdO}$ or $\operatorname{In}(\mathrm{OH})_{3}$, the ratio of the discharge capacity to the charge capacity was increased and the discharge overpotential was decreased with repeating of charge and discharge. In this case, however, the amount of $\mathrm{HgO}$ formed by charging decreased with repeating as shown in Fig. 1. At present, the details are unknown why these phenomena were observed. But it is considered that the effects of these additives became apparent due to the mixing of $\mathrm{Cd}, \mathrm{Zn}$ or In into $\mathrm{HgO}$. As mentioned above, by adding $\mathrm{CdO}$ or $\mathrm{ZnO}$, the selfdischarge reaction was not accelerated, but by adding $\mathrm{In}(\mathrm{OH})_{3}$ or $\mathrm{SnO}$, it was considerably accelerated. By adding $\mathrm{Ag}_{2} \mathrm{O}$ the self-discharge reaction became comparatively large, yet not so large as that for $\mathrm{In}(\mathrm{OH})_{3}$ or $\mathrm{SnO}$. By adding $\mathrm{SnO}$, the reaction of Eq. (1) was accelerated dut to oxidation of $\mathrm{Sn}^{2+}$ to $\mathrm{Sn}^{4+}$, which promoted the self-discharge.

From above results, $\mathrm{Cd}$ or $\mathrm{Zn}$ added into the mercuric oxide electrode in the state of complex ions can accelerate the disproportionate reaction which is the rate determing step for the discharge of the mercuric oxide electrode. Therefore it is possible to decrease the discharge overpotential. Moreover these complex ions give very effective behavior for improving the discharge performance because of no existence of accelerating effect of the self-discharge*.

Then, the oxides or hydroxides of transition metals were selected and discussed for improving the discharge performance. Fig. 3 (b) shows this result. As representative examples, the effects of $\mathrm{Fe}(\mathrm{OH})_{3}$, $\mathrm{La}_{2} \mathrm{O}_{3}$ and $\mathrm{Ce}(\mathrm{OH})_{4}$ were discussed. In all cases the discharge overpotential of the mercuric oxide electrode decreased exceedingly, so the decomposition reaction due to the disproportionate reaction of the intermediate product formed during discharge was accelerated. The self-discharge reaction of the mercuric oxide electrode was accelerated by adding $\mathrm{Ce}(\mathrm{OH})_{4}$, but it was much retarded by adding $\mathrm{Fe}(\mathrm{OH})_{3}$

\footnotetext{
* Cd or $\mathrm{Zn}$ added by the amalgamation method decreased the discharge overpotential but accelerated the self-discharged of the mercuric oxide electrode. In this case the amount of $\mathrm{HgO}$ formed by anodic oxidation is exceedingly small and yet large amount of amalgam exists under $\mathrm{HgO}$. Therefore total amount of the additive is considerably much as compared with $\mathrm{HgO}$ formed. For this reason the self-discharge was accelerated. However, practical mercury dry cell has a large volume of $\mathrm{HgO}$ as compared with $\mathrm{Hg}$ and should not have the additive enough to advance Eq. (1) for a trace of the additive as amalgam, so both the additives by the amalgamation method and by the saturation method are considered to exhibit the same effect.
} 
$\mathrm{NiO}$ or $\mathrm{La}_{2} \mathrm{O}_{3}$ and in this case, the utilization ratio of $\mathrm{HgO}$ became $5-10 \%$ higher than that for no additive. Namely, $\mathrm{Fe}(\mathrm{OH})_{3}, \mathrm{NiO}$ and $\mathrm{La}_{2} \mathrm{O}_{3}$ are considered to be very excellent additives for improving the discharge performance of the mercuric oxide electrode. Fig. 4 (2) and Fig. 4 (3) show the potential change after closing and opening of the circuitd uring discharge for the additives in the state of complex ions in the electrolyte by the saturation method. In this case the discharge overpotential was lowered more than that for no additive and the potential drop at the equilibrium state after opening of the circuit, as observed in the case of the amalgamation method, did not appear. These phenomena verify the above result more distinctly.

Fig. 5 shows the relationship between the overpotential and the discharge current in the equilibrium state of the discharge reaction at constant current. The additives were all introduced by the saturation method. The same tendency as that for no additive was obtained by adding $\mathrm{Ag}_{2} \mathrm{O}$, on the other hand, by adding $\mathrm{CdO}, \mathrm{ZnO}, \mathrm{Fe}(\mathrm{OH})_{4}$ or $\mathrm{La}_{2} \mathrm{O}_{3}$ the discharge overpotential was decreased, and so the decomposition action of the intermediate product formed during discharge was much accelerated.

Table 1 summarizes the above results. Various kinds of the additives are classified in four groups. The additives of the first group decreased the discharge overpotential but accelerated the self-discharge of mercuric oxide electrode, so these additives belong to the harmful ones. The additives on the second group scarcely influenced the discharge reaction

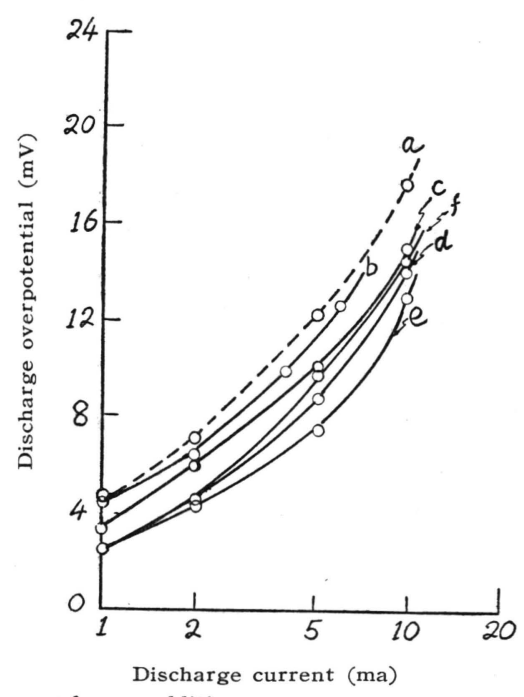

a : for no additive

b : for AgO by the saturation method

c : for $\mathrm{ZnO}$ by the saturation method

$\mathrm{d}$ : for CdO by the saturation method

e : :or $\mathrm{Fe}\left(\mathrm{OH}_{3}\right)$ by the saturation method

$f$ : for $\mathrm{La}_{2} \mathrm{O}_{3}$ by the saturation method

Fig. 5 Relation between the discharge current and the overpotential of the equilibrium state after discharge at constant current

Table 1 Discharge Performance of the Mercuric Oxide Electrode for the Various Additive (Experiment in $30^{\circ} \mathrm{C}, 1 \mathrm{~N}$ - $\mathrm{KOH}$ electrolyte)

\begin{tabular}{|c|c|c|c|c|c|c|c|c|}
\hline \multicolumn{2}{|c|}{ Group } & Examples & Amount & $\begin{array}{l}\text { Discharge capa- } \\
\text { city }\end{array}$ & $\begin{array}{l}\text { Ratio of dis- } \\
\text { charge }(\%)\end{array}$ & Over-potential & $\begin{array}{l}\text { Self-discharge } \\
\text { current }\end{array}$ & Additives \\
\hline \multirow{3}{*}{ I } & $\mathrm{a}$ & $\mathrm{Sn}^{*}$ & 0.005 & 21.6 & 4 & 1.5 & 3.2 & $\mathrm{Sn}^{*} \mathrm{Cd}^{*}$ \\
\hline & \multirow{2}{*}{$\mathrm{b}$} & $\mathrm{Pb}^{*}$ & 0.01 & 20.3 & 25 & 2.0 & 1.8 & $\mathrm{~Pb}^{*} \mathrm{Cu}^{*}$ \\
\hline & & $\mathrm{Cu}^{*}$ & 0.01 & 13.6 & 16 & 2.0 & 1.8 & $\mathrm{In}^{*} \mathrm{Zn}{ }^{*} \mathrm{Tl}^{*}$ \\
\hline \multirow[b]{2}{*}{ II } & $\mathrm{a}$ & $\mathrm{Ag}^{*}$ & 0.5 & 21.6 & 92 & 4.5 & 0.06 & $\mathrm{Ag}^{*} \mathrm{Au}^{*}$ \\
\hline & b & $\mathrm{Ag}_{2} \mathrm{O}$ & $\begin{array}{l}\text { saturated in } \\
1 N-\mathrm{KOH}\end{array}$ & 28.3 & 82 & 4.5 & 0.15 & $\mathrm{Ag}_{2} \mathrm{O}$ \\
\hline \multirow{4}{*}{\multicolumn{2}{|c|}{ III }} & $\mathrm{CdO}^{1)}$ & & 26.7 & 91 & 4.5 & 0.07 & $\mathrm{CdO}$ \\
\hline & & $\mathrm{CdO}^{2)}$ & saturated in & 9.3 & 95 & 1.5 & 0.04 & $\mathrm{ZnO}$ \\
\hline & & $\mathrm{ZnO}$ & $1 \mathrm{~N}-\mathrm{KOH}$ & 33.2 & 81 & 3.5 & 0.25 & $\mathrm{SnO}$ \\
\hline & & $\operatorname{In}(\mathrm{OH})_{3}$ & & 45.0 & 73 & 3.5 & 0.34 & $\operatorname{In}(\mathrm{OH})_{3}$ \\
\hline \multirow{4}{*}{ IV } & a & $\mathrm{NiO}$ & saturated & 14.1 & 91 & 2.0 & 0.07 & $\mathrm{NiO}$ \\
\hline & & $\mathrm{Fe}(\mathrm{OH})_{3}$ & & 28.0 & 93 & 2.5 & 0.06 & $\mathrm{Fe}(\mathrm{OH})_{2}$ \\
\hline & \multirow{2}{*}{$\mathrm{b}$} & $\mathrm{Ce}(\mathrm{OH})_{4}$ & saturated & 19.3 & 82 & 2.0 & 0.16 & $\mathrm{Ce}(\mathrm{OH})_{4}$ \\
\hline & & $\mathrm{La}_{2} \mathrm{O}_{3}$ & & 19.2 & 95 & 2.5 & 0.05 & $\mathrm{La}_{2} \mathrm{O}_{3}$ \\
\hline \multicolumn{2}{|c|}{ V } & $\begin{array}{l}\text { for no ad- } \\
\text { ditive }\end{array}$ & - & 20.0 & 90 & 4.5 & 0.07 & - \\
\hline
\end{tabular}

Note: $\left(^{*}\right)$ is by the saturation method.

The others are by the saturation method.

$\mathrm{CdO}^{1)}$ is for the first discharge.

$\mathrm{CdO}^{2)}$ is after three cycles of charge and discharge (charge at $6 \mathrm{ma}$, discharge at $1 \mathrm{~mA}$ ). 
of the mercuric oxide electrode, only except slight retard of the self-discharge. The additives of the third and fourth groups decreased the discharge overpotential and retarded or did not influence the self-discharge reaction of the mercuric oxide electrode, especially, $\mathrm{CdO}, \mathrm{ZnO}, \mathrm{Fe}(\mathrm{OH})_{3}, \mathrm{NiO}$ and $\mathrm{La}_{2} \mathrm{O}_{3}$ were exceedingìy effective for improving the discharge performance of the mercuric oxide electrode. The overpotential in Table 1 was measured after 5-10\% discharge of the charging capacity and the seif-discharge current was calculated on the assumption that the self-discharge was progressing at constant rate all the time during anodic oxidation, the open circuit and discharge of the electrode.

Fig. 6 shows the overpotential-current curves at different temperatures in the case of adding $\mathrm{La}_{2} \mathrm{O}_{3}$ by the saturation method which gave the best discharge performance. Moreover the result for no additive reported in the previous paper ${ }^{1)}$ is shown in Fig. 6. Both curves in Fig. 6 exhibit the same tendency, that is, the overpotential decreased with higher temperature and also the relationship between the discharge overpotential and the current exhibits the same tendency at different temperatures. $\mathrm{La}_{2} \mathrm{O}_{3}$ decreased considerably the discharge overpotential of the mercuric oxide electrode in comparison with that for no additive.

The theoretical equation relating the discharge current and the overpotential, as described in the previous paper $^{1)}$,

$$
I=\frac{K_{2}}{1-L_{e}} \exp \left\{\frac{F 2(\Delta E e)}{R T}\right\}-K_{2}
$$

was discussed for the case of adding $\mathrm{La}_{2} \mathrm{O}_{3} *$. Fig. 7 shows this result, which has linear relation between the discharge current $I$ and $\exp \left\{\frac{2 F(\Delta E e)}{R T}\right\}$. The assumption described in the previous paper ${ }^{1)}$ could be applied similarly to the case of adding $\mathrm{La}_{2} \mathrm{O}_{3}$. In Fig. 7, $1-L_{e} \doteqdot 1$ indicates no existence of the intermediate product on the electrode surface at the equilibrium state after opening of the circuit. $K_{2}$ was in accord with the qualitative result that it increased with higher temperature. When $\log _{10} K_{2}$ was plotted against $1 / T$ in accordance with the Arrhenius' equation, a straight line was obtained as shown in Fig. 8. Arrhenius' constant evaluated from the

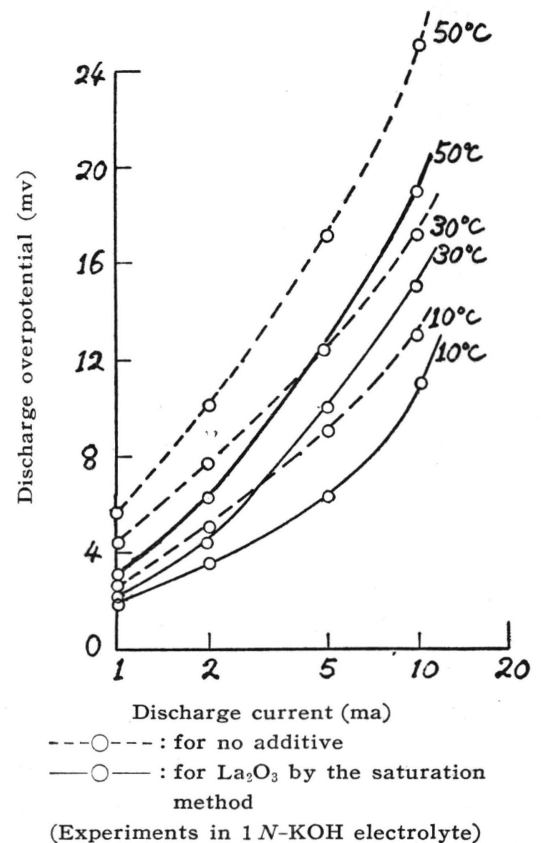

Fig. 6 Relation between the discharge overpotential and the discharge current for various temperatures

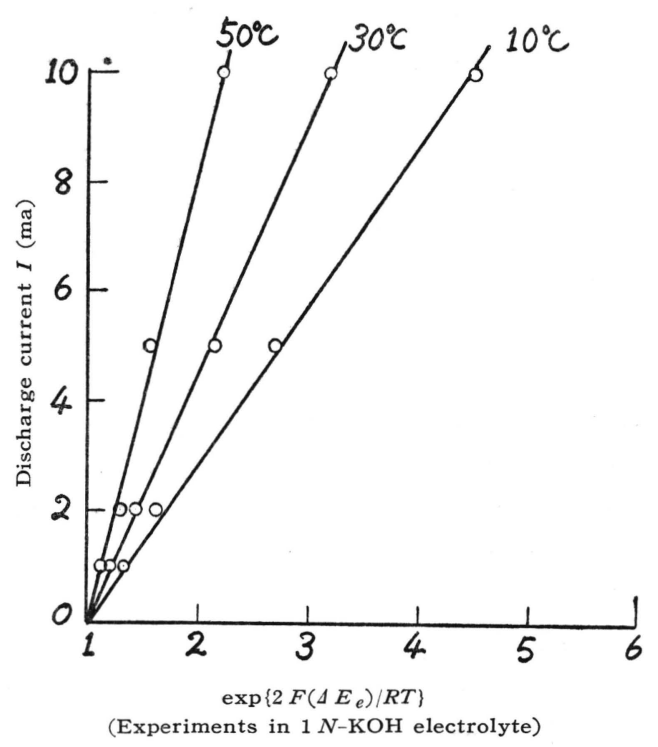

Fig. 7 Relation between $\exp \left\{2 \mathrm{~F}\left(\Delta E_{e}\right) / R T\right\}$ and the discharge current for $\mathrm{La}_{2} \mathrm{O}_{3}$ by the saturation method at various temperatures gradient of this straight line was $4.98 \mathrm{kcal} / \mathrm{mol}$. This Arrhenius' constant for the mercuric oxide elec-

* I : discharge current, $E_{e}$ : discharge overpotential, $L_{e}:$ mol fraction of an intermediate product $\left(\mathrm{Hg}_{2} \mathrm{O}\right)_{1 / 2}$ or $\mathrm{HgOH}_{\mathrm{O}}$ exsisting on the electrode surface at the equlibrium state after opening of the circuit, $K_{2}: k_{2} / k^{\prime}$, here $k_{2}$ is the rate constant of reverse direction of Eq. (2), $k^{\prime}$ is the amount of the intermediate product formed per unit time and unit current during discharge. 


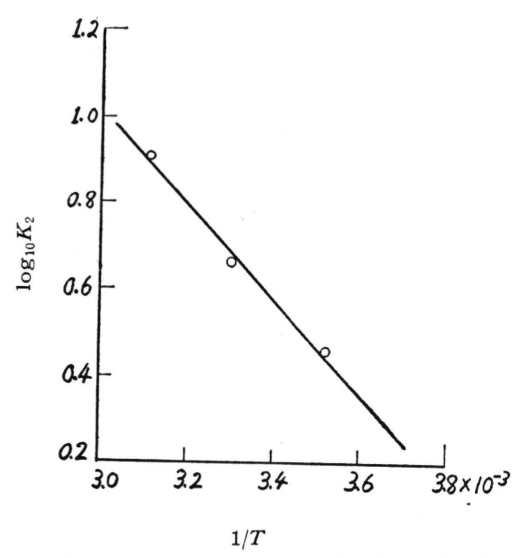

(Experiments in $1 \mathrm{~N}$-KOH electrolyte)

Fig. 8 Relation between $1 / T$ and $\log _{10} K_{2}$ for $\mathrm{La}_{2} \mathrm{O}_{3}$ during discharge

trode with no additives had been $5.41 \mathrm{kcal} / \mathrm{mol}$ as described in the previous paper ${ }^{11}$. Therefore, it was found that $\mathrm{La}_{2} \mathrm{O}_{3}$ decreased the activation energy of the decomposition reaction of the intermediate product formed during discharge of the mercuric oxide electrode.

\section{Conclusion}

The effects of a trace of the various additives on the discharge reaction of the mercuric oxide electrode were discussed. The electrode prepared by anodic oxidation in $\mathrm{KOH}$ solution was adopted as the mercuric oxide electrode. The additives were either added to the electrode as amalgam or saturated in the electrolyte as the state of complex ions of the oxides or hydroxides.

(1) Various kinds of the additives influenced the disproportionate decomposition of intermediate compound which was the rate determining step of the discharge reaction of the mercuric oxide electrode.

(2) When the additive metals may be readily oxidized, their oxidation reaction is combined with the discharge reaction of the mercuric oxide electrode, so that the self-discharge reaction is accelerated due to the local cell.

(3) The former case (1) influences the discharge overpotential, the latter case (2) influences the discharge capacity ratio to the charging capacity.

(4) Those metals which are more electro-negative than mercury such as $\mathrm{Cu}, \mathrm{Zn}, \mathrm{Cd}, \mathrm{In}, \mathrm{Tl}$, Sn or $\mathrm{Pb}$ exceedingly decreased the discharge overpotential and accelerated the self-discharge reaction which occurred due to the local cell formed by the ionization reaction of these metals.

(5) Those metals which are more electro-positive than mercury or the oxides of these metals such as $\mathrm{Au}, \mathrm{Ag}$ or $\mathrm{Ag}_{2} \mathrm{O}$ scarcely influenced the discharge reaction except slight retard of the self-discharge.

(6) The oxides or hydroxides of easily amalgamating metals or transition metals added in the electrolyte by the saturation method decreased the discharge overpotential and retarded the selfdischarge of the mercuric oxide electrode. In particular, $\mathrm{CdO}, \mathrm{ZnO}, \mathrm{Fe}(\mathrm{OH})_{3}, \mathrm{NiO}$ and $\mathrm{La}_{2} \mathrm{O}_{3}$ were exceedingly effective additives for improving the discharge performance.

(7) The theoretical equation relating between the discharge current and the discharge overpotential as shown for no additive in the previous paper ${ }^{1)}$ was applied to the mercuric oxide electrode containing a trace of the additive of $\mathrm{La}_{2} \mathrm{O}_{3}$. Good result in accord with the assumption of the previous paper ${ }^{1)}$ was obtained. Also the activation energy of the decomposition reaction of the intermediate product formed during discharge decreased considerably due to the additives such as $\mathrm{La}_{2} \mathrm{O}_{3}$.

(Received Dec. 28, 1962)

\section{Literature :}

1) S. Yoshizawa, Z. Takehara, Denki-Kagaku 30, 399 (1962); J. Electrochem. Soc. Japan, 30, (1962). 